\title{
Invertebrate Biology
}

\section{Growing or reproducing in a temperate sea: Optimization of resource allocation in a colonial ascidian}

\begin{tabular}{|r|l|}
\hline Journal: & Invertebrate Biology \\
\hline Manuscript ID: & Draft \\
\hline Danuscript Type: & Original Manuscript \\
\hline Complete List of Authors: & n/a \\
\hline & $\begin{array}{l}\text { López-Legentil, Susanna; University of Barcelona - Faculty of Biology, } \\
\text { Department of Animal Biology (Invertebrates) } \\
\text { Erwinertebrates) } \text { (Iniversity of Barcelona, Department of Animal Biology } \\
\text { Velasco, Marta; University of Barcelona, Department of Animal Biology } \\
\text { (Invertebrates) } \\
\text { Turon, Xavier; Center for Advanced Studies of Blanes, }\end{array}$ \\
\hline Keywords: & Tunicate, Growth rate, Maturity index, Mediterranean Sea, Temperature \\
\hline
\end{tabular}

SCHOLARONE $^{\text {'M }}$

Manuscripts 
1 Formatted for: Invertebrate Biology

2

3

4 Growing or reproducing in a temperate sea: Optimization of resource allocation in a colonial ascidian

6

7 Susanna López-Legentil ${ }^{1, *}$, Patrick M. Erwin $^{1}$, Marta Velasco ${ }^{1}$ and Xavier Turon ${ }^{2}$

8

$9{ }^{1}$ Department of Animal Biology, University of Barcelona, Diagonal Avenue 643, 10

$11{ }^{2}$ Center for Advanced Studies of Blanes (CEAB-CSIC), Accés Cala S. Francesc 14, 12 17300 Blanes, Girona, Spain

13 14

15 *Corresponding author: Susanna López-Legentil. Tel. +34 93403 1150; Fax. +34 93

16403 5740; Email. slopez@ub.edu

17

18 Running title: Life cycle of the colonial ascidian Didemnum fulgens

19

An international journal of the American Microscopical Society and the Division of Invertebrate $1_{\text {Zoology/SICB }}$ 
20 Abstract. To date, there is still little information about the life cycles of ascidians in 21 temperate seas. Here, we investigated the biological cycle of the colonial ascidian 22 Didemnum fulgens, a dominant species in some shallow localities of the NW

23 Mediterranean Sea. Growth rates and frequency of fission/fusion events were

24 calculated over a period of 13 months and the reproductive cycle determined after 32

25 months of observation. For reproduction analyses, zooids were dissected in the

26 laboratory and classified in 5 reproductive categories used to calculate a maturity

27 index. For growth analysis, underwater photographs of marked colonies were used to

28 quantify the surface area of D. fulgens colonies, calculate monthly growth rates, and

29 document fusion and fission events. Clear seasonal patterns in reproduction and

30 growth were observed in $D$. fulgens, with distinct periods of investment in each

31 function. Gonad maturation started in winter and larval release occurred in early

32 summer, just before maximal sea temperatures were reached. After reproducing,

33 colonies shrank and aestivated during the warmer summer months. Growth occurred

34 during the cooler months, with maximal and minimal growth rates observed in winter

35 and summer respectively. Fusions and fissions occurred year-round although fissions

36 were more frequent in fall (coincident with high growth rates) and fusions in spring

37 (coincident with reproduction). These results add to mounting evidence that ascidian

38 life cycles in temperate seas are characterized by a trade-off between investment in

39 reproduction and growth, triggered by seasonal temperature shifts and constrained by

40 resource availability during summer.

41

42 Additional key words: Tunicate, growth rate, Mediterranean Sea, maturity index, 43 temperature

44

45 
46

47

48

49

50

51

52

53

54

55

56

57

58

59

60

61

62

63

64

65

66

67

68

69

70

\section{Introduction}

Ascidians or sea-squirts (Chordata; Tunicata) are sessile, filter-feeding organisms that occur in benthic ecosystems across a broad range of depths and latitudes (Lambert 2005). These animals are notorious for their detrimental effects on aquaculture facilities, as fouling organisms attached to ship hulls (Turner et al. 1997; Rodriguez and Ibarra-Obando 2008; Hewitt et al. 2009; Carman et al. 2010), and as introduced and invasive species (e.g. Didemnum vexillium, Lambert 2009; Stefaniak et al. 2009, 2012). In addition, ascidians have been utilized as bioindicators of pollution (Agell et al. 2004; Carman 2007; Azumi et al. 2008) and as a source of bioactive secondary metabolites for anti-cancer drug research (Erwin et al. 2010). Thus, while their ecological and biotechnological importance is well known, comparatively little is known about their biology and, in particular, their growth and reproductive strategies. Ascidians are hermaphroditic and mostly reproduce through sexual crossfertilization, resulting in the production of free-living, non-feeding larvae that must find a suitable substrate to settle and metamorphose in a matter of hours to days (Svane and Young 1989; Rius et al. 2010). Solitary ascidians are normally oviparous, while colonial ascidians usually brood their larvae. Colonial ascidians can also experience fission and fusion events. Fission is a phenomenon by which an existing colony divides to generate two or more smaller colonies and is considered an asexual method for colony proliferation. In contrast, fusion is the union of two or more colonies that results in rapid growth. In didemnid ascidians, colonies appear to fuse indiscriminately (Bishop and Sommerfeldt 1999), while in botryllids fusion is regulated by genetic histocompatibility (Rinkevich and Saito 1992; Saito et al. 1994; Rinkevich 2005). In fact, within colonial ascidians, most of available information on 
71 reproductive ecology and colonial dynamics refers to botryllid ascidians (e.g. Newlon

72 III et al. 2003; Bates 2005; Rinkevich 2005; Marshall et al. 2006; Westerman et al.

73 2009). In contrast, much less is known about enterogonid families of colonial

74 ascidians (e.g. Bishop and Sommerfeldt 1999; Dias et al. 2008; Shenkar et al. 2008).

75 In general, marine species that live in warmer waters reproduce and grow

76 throughout the year, while those that live in temperate seas tend to exhibit seasonal

77 life cycles (Coma et al. 2000; Hernández-Zanuy et al. 2000; Fukuda and Hirose 2008;

78 Shenkar and Loya 2008; Ritzmann et al. 2009). In the Mediterranean, most colonial

79 ascidian species reproduce before maximal sea temperatures are reached in summer

80 (Turon 1988; Turon and Becerro 1992; Molin et al. 2003; López-Legentil et al. 2005),

81 while a few do so during the cooler months of the year (e.g. Aplidium spp., Turon

82 1988; Turon and Becerro 1992). Similarly, most of the colonial ascidians studied

83 experience positive growth during fall and winter (Turon and Becerro 1992; López-

84 Legentil et al. 2005; Pérez-Portela et al. 2007) and no species has been observed to

85 actively grow during the summer months. Millar (1971) proposed temperature as the

86 main factor regulating the life cycles of temperate ascidians, but other parameters,

87 such as limited resource availability (Bates 2005; Lambert 2005), turbidity (Millar

88 1971), currents and wave exposure (Shenkar and Loya 2008), or competing

89 invertebrate species (Dias et al. 2008; Stocker and Underwood 1991) may also

90 influence their life cycles. A trade-off between reproduction and growth has also been

91 observed in some ascidians, suggesting a partitioning of resources to specific

92 biological functions (López-Legentil et al. 2005; Pérez-Portela et al. 2007). In fact,

93 López-Legentil et al. (2007) showed that reproduction was the main factor driving

94 both growth and defense production in a temperate ascidian species. 
95

96

97

98

99

100

101

102

103

104

105

106

107

108

109

110

111

112

113

114

115

116

117

118

119

Aestivation periods and resting forms are also common in ascidians living in temperate seas. Resting periods normally occur during the unfavorable season, which for most Mediterranean filter-feeders is summer (Coma et al. 2000). The function of aestivation is not well understood in ascidians and several hypotheses have been suggested for different species. Berrill (1951) described a regression period after reproduction that involved tissue reorganization. Burighel et al. (1976) suggested an excretory role of degenerative residues. Turon (1992) proposed a 'rejuvenative' process that involved the regression of old thoraces and budding of new ones, and Molin et al. (2003) suggested a propagative budding to generate new zooids after reproduction. Although the reason for aestivation and resting is not clear, this phenomenon appears to be widespread among ascidians in the Order Aplousobranchia, affecting many species from several different families (e.g. Polysyncraton lacazei, Didemnidae, Turon 1992; Pseudodistoma crucigaster, Pseudodistomidae, Turon and Becerro 1992; Polycitor adriaticus, Polycitoridae, Molin et al. 2003; and Pycnoclavella spp., Clavelinidae, Pérez-Portela et al. 2007). Didemnid ascidians can be dominant organisms in sublittoral communities (e.g. Bak et al. 1981; Ryland et al. 1984; Stocker 1991), especially when they become invasive (e.g. Kremer et al. 2010; Lambert 2009; Smale and Childs 2012). Thus, the study of their population dynamics and life cycles is useful to explain processes such as space occupation and community diversity patterns (Dijkstra et al. 2007; Dijkstra and Harris 2009; Fiore and Cox Jutte 2010). During the last decade, populations of the didemnid ascidian Didemnum fulgens (MILNE-EDWARDS 1841) have increased in the NE coast of Spain, from a rarely reported species to a common ascidian in rocky infralittoral communities (pers. obs.) and on the rhizomes of the seagrass Posidonia oceanica (Balata et al. 2007). The recent expansion of D. fulgens, in terms of 
120 population numbers and sizes, raises questions about the environmental shifts that

121 may have facilitated the spread of this species and the biological characteristics that

122 have allowed it to outcompete resident sessile organisms. The goal of this study was

123 to determine the seasonal cycles of reproduction and growth in the colonial ascidian

124 D. fulgens and assess whether a trade-off in resource allocation exists between these

125 two biological functions. To address these questions, we assessed the reproductive

126 cycle of $D$. fulgens by characterizing reproductive status monthly for over 2.5 years

127 and determined the growth rate and number of fission/fusion events monthly for 1

128 year using underwater transects and digital photography.

\section{Methods}

131

132 Sample site and species identification

133

134 This study was conducted in a coastal site of the Mediterranean Sea located between

135 l'Illa Mateua and Cala Montgó in L'Escala (NE Spain, 42 $7^{\prime}$ 29’’ N, 3 7’ 57’’ E).

136 Since previous studies conducted in this area during the early 2000 s, we have

137 observed the proliferation of an orange-pinkish didemnid that has rapidly become a

138 conspicuous species in shallow rocky communities reaching densities of ca. 7

139 colonies $/ \mathrm{m}^{2}$.

140 The species was identified following descriptions by Lafargue (1976), and

141 Lafargue and Wahl (1987). In short, Didemnum fulgens is characterized by bright

142 orange colonies, dense calcareous spicules (up to $50 \mu \mathrm{m}$ in diameter) with short,

143 pointed rays (about 20 visible), zooids with small thoracic organs in the posterior part 
144 of the thorax, a sperm-duct with 7-9 coils, and larvae with two adhesive papillae and

145 4-6 pairs of epidermal ampullae.

146 To barcode this ascidian species, one colony was preserved in $100 \%$ ethanol

147 and stored at $-20^{\circ} \mathrm{C}$ until processed. Zooids were carefully separated from the tunic

148 under a stereomicroscope and DNA was extracted using the DNeasy Blood \& Tissue

149 kit (Qiagen). The primer set Tun_forward and Tun_reverse2 described by Stefaniak et

150 al. (2009) was used to amplify a fragment of the Cytochrome $c$ Oxidase subunit I

151 (COI) mitochondrial gene. Total PCR reaction volume was $25 \mu$, including 5 pmol of

152 each primer, $5 \mathrm{nmol}$ of each dNTP, 1x reaction buffer (Ecogen), and 2.5 units of

153 BIOTAQ polymerase (Ecogen). PCR program included initial denaturing at $94^{\circ} \mathrm{C}$ for

$1545 \mathrm{~min}$, followed by 40 amplification cycles of $94^{\circ} \mathrm{C}$ for $30 \mathrm{sec}$; annealing at $40^{\circ} \mathrm{C}$ for

$15530 \mathrm{sec}$; and extension at $72^{\circ} \mathrm{C}$ for $1 \mathrm{~min}$, and a final extension at $72^{\circ} \mathrm{C}$ for $10 \mathrm{~min}$.

156 Cleaning and sequencing reactions were carried out at Macrogen, Inc. (Seoul, Korea).

157 The resulting sequence has been deposited in the GenBank database (Acc. No.

158 JX846617) and BLAST searches revealed another didemnid species as best match $(D$.

159 perlucidum JQ731735, 88\% similarity).

160

161 Sample collection and monitoring

162

163 To determine the reproductive cycle of $D$. fulgens, 5 colonies were collected and

164 immediately fixed in 10\% formaldehyde every month from June 2009 to May 2012

165 by SCUBA diving. Colonies were separated by at least $5 \mathrm{~m}$ and collection depth

166 ranged from 4 to 10.5 meters. From April 2011 to May 2012, a permanent $3.5 \mathrm{~m}$

167 horizontal transect at $7 \mathrm{~m}$ depth was established along a vertical wall and the position

168 of each colony of D. fulgens sketched underwater on a plastic slate. Each colony was 
169 revisited monthly and photographed with an Olympus PT-027 underwater camera

170 fixed to an aluminum frame $(18.7 \mathrm{~cm} \mathrm{x} 13 \mathrm{~cm})$ to keep a constant focal distance.

171 Seawater temperature was recorded using either a HOBO ${ }^{\circledR}$ Pendant Temperature

172 Data Logger (Onset Computer Corporation) which registered temperature each hour,

173 or a diving computer during the periods in which no datalogger was deployed. No

174 sampling could be performed in December 2009, April 2010, September 2010,

175 November 2010 and February 2012 because of unfavorable diving conditions. For

176 these months, seawater temperatures were calculated as an average of the previous

177 and following months' temperatures.

178

179 Reproductive cycle

180

181 Once in the laboratory, colonies fixed in $10 \%$ formaldehyde were dissected under a

182 stereomicroscope and 10 zooids per colony were carefully observed to determine their

183 reproductive status. Each zooid was scored according to the following categories: (1)

184 immature, (2) presence of testes, (3) presence of testes and oocytes and (4) presence

185 of oocytes. A maturity index (MI, Lopez-Legentil et al. 2005) was calculated for each

186 colony by averaging the category number of the zooids examined, except when larvae

187 were observed in the basal tunic. Colonies with larvae were scored with a maturity

188 index value of 5 since larval production represents the culmination of reproduction

189 and zooids regress to immature status during the brooding period. Monthly means

190 were calculated by averaging the values of the colonies investigated that month.

191

192 Growth cycle

193 
194 Since $D$. fulgens presents a thinly encrusting morphology, changes in the surface area 195 over time were calculated as an estimate of growth. The surface area of each colony 196 was measured using the image analysis software ImageJ v. 1.45s. Fission and fusion 197 events were also recorded. The nature of these events, whether they occur among 198 colonies with the same genotype or different genotypes (chimeras), is unknown for $D$. 199 fulgens. In this study, we grouped together colonies resulting from a fusion or fission 200 event into 33 groups or 'growth units'. When fusion occurred, the areas of the 201 previous colonies were added together to obtain a single value for each unit. When 202 fission occurred, areas of the resulting colonies were added (Turon and Becerro 203 1992). Monthly growth rates (GR) were calculated as follows:

$204 G R_{m}=\frac{\left(A_{m}-A_{m-1}\right)}{A_{m-1}}$

205 Where $A_{m}$ and $A_{m-1}$ are the areas at month $m$ and at the previous month $(m-1)$

206 respectively. These values were then smoothed to avoid noisy fluctuations using a

207 weighed moving average: the value of the current month $\left(\mathrm{GR}_{\mathrm{m}}\right)$ multiplied by 0.5 plus

208 values of the previous $\left(\mathrm{GR}_{\mathrm{m}-1}\right)$ and subsequent $\left(\mathrm{GR}_{\mathrm{m}+1}\right)$ months multiplied by 0.25 . 209

\section{Cross-correlation analysis}

212 Cross-correlation analyses were used to establish relationships between growth rate, 213 maturity index, and temperature over time. In cross-correlations, two series of data are 214 compared as a function of a time lag $(n)$, using the Pearson correlation coefficient to 215 measure relationships between values of the first data series and values of the second 216 series $n$ months earlier (in negative lags) or later (in positive lags). Correlation 
217 coefficient values at lag 0 are equivalent to the standard Pearson correlation. We used

218 Systat v. 12.02 package for the analyses.

219

220

\section{Results}

221

222

\section{Reproductive cycle}

223

224 The time course of the main reproductive categories established for Didemnum

225 fulgens (Figure 1) showed a marked seasonal fluctuation in reproduction, with larval

226 release occurring mostly in spring and early summer. Immature zooids were recorded

227 all year round but were more abundant from July/August to December in the three

228 investigated years. Zooids with testes were present from January to April, zooids

229 combining testes and oocytes were found from March to May and zooids with only

230 oocytes were present from May to June. Larval release occurred in early summer before

231 the warmest sea temperatures were reached. Years with sharp increases in temperature

232 coincided with a shorter larval release period (e.g. one month in 2010) while slower

233 increases of temperature were accompanied by longer spawning events (e.g. three months

234 in 2011).

235 The maturity index (MI) increased in winter and achieved its maximum

236 around June each year, coinciding with the brooding period (Figure 2). After June, MI

237 decreased abruptly before seawater temperature reached its maximum, and maintained

238 low values until the following winter. Cross-correlation analysis showed a significant

239 negative correlation between the maturity index and the water temperature measured a

240 few months before (Figure 3). A MI rise was therefore preceded by a temperature

241 minimum one to four months before (time lag -1 to -4). The wave-like form of the cross- 
242 correlation plot, with peaks separated by ca. 6 months, reflected the seasonal nature of 243 the evolution of both temperature and MI.

244 Most colonies entered into a resting state after reproduction that was

245 maintained during the warmer months of the year (June, July, and August). The

246 resting form was characterized by a closure of all inhalant siphons and a 'leather-like'

247 appearance of the colonies (Figure 4). Most colonies resumed filtering (i.e. opened

248 inhalant siphons) in September and by October all colonies were actively feeding.

250 Growth cycle

251

252 Overall, the mean area of the colonies surveyed increased $261 \%$ ( $\pm 81 \mathrm{SE})$ during the 253 study period (Figure 5). Growth rates showed a clear seasonal trend, with lower 254 values in spring and summer and higher values in fall and winter (Figure 6). A total of 25518 fusions and 24 fissions occurred in $51 \%$ of the colonies surveyed (Figure 7).

256 Fusions and fissions were recorded throughout the year although fusions were more 257 abundant in spring and fissions in fall (Figure 7). Fusions mainly occurred in May and 258 April after most of the colonies reached their maximal growth rate. Most fissions 259 occurred from June to January, corresponding with reactivation after summer 260 dormancy and lower levels of growth. Cross-correlation results indicated that growth 261 was significantly correlated with temperature, as growth rates increased in the colder 262 months and decreased in the warmer months (Figure 8A). There was a negative and 263 significant correlation at time lags $-1,0,1$ and 2 (Figure 8A). Thus, growth rates were 264 negatively correlated with the current water temperature and the temperature in the 265 previous and following one to two months. 
266 Relationships between growth and reproduction were investigated to look for

267 potential trade-offs in the allocation of energy resources. Our results showed opposite

268 trends for the two variables: when the maturity index increased, growth rates decreased

269 and vice versa (Figure 8B). Cross-correlation analyses further confirmed this observation

270 revealing a significant negative correlation between growth rate and the maturity index at

271 time lags -1 and -2 , indicating that higher investment in reproduction in the previous one

272 and two months was related with lower current growth (Figure 8B).

273

274

275

276

277

278

279

280

281

282

283

284

285

286

287

288

289

290

\section{Discussion}

The colonial ascidian Didemnum fulgens presented a clear seasonal life cycle alternating between reproduction and growth. Maturation of the gonads started in winter and culminated with larvae release in early summer, just before maximal sea temperatures were reached. After spawning, colonies went into aestivation coinciding with the warmer months of the year. Growth started in fall and continued during winter, with a decrease in spring at the time of the rise of the maturity index.

Reproduction was positively correlated with seawater temperature in the previous months, while growth rates were negatively correlated with current temperature and with investment in reproduction during the preceding months.

Temperature has often been reported as the main abiotic factor triggering ascidian life cycles in temperate seas (e.g. de Caralt et al. 2002; López-Legentil et al. 2005; Pérez-Portela et al. 2007). Likewise, both the reproduction and growth cycles of D. fulgens were tightly correlated with temperature shifts over time. In the Mediterranean, ascidians reproduce either before or after maximal seawater temperatures are reached, with reproductive timing related to the biogeographical 
291 distribution of each ascidian species. Atlanto-Mediterranean species that have cold-

292 water affinities reproduce during winter, while endemic or Senegalian species

293 reproduce in spring-early summer (Turon 1988). Moreover, the duration of the

294 reproductive period in ascidians may also be related to the rate at which maximal

295 seawater temperatures are reached each year. For instance, in our study we found that

296 years with sharp increases in temperature coincided with a shorter larval release

297 period (e.g. 2010) while slower increases of temperature were accompanied by longer

298 spawning events (e.g. 2011). Similarly, Pérez-Portela et al. (2007) showed that when

299 seawater temperature increased sharply, Pycnoclavella aurilucens incubated larva for

300 two months, while incubation could last up to four months when maximal

301 temperatures were reached more progressively. To date, there is less than a handful

302 studies describing ascidian life cycles during more than two years. Although long-

303 term monitoring studies are labor-intense and time consuming, they remain necessary

304 to acquire a thorough understanding of the factors that influence ascidian life cycles in

305 temperate seas.

306 Aestivation periods and resting forms are common in Mediterranean ascidians

307 and have been ascribed to unfavorable conditions, such as high seawater temperatures

308 and decreases in food availability for filter-feeding organisms (Coma and Ribes 2003;

309 Coma et al. 2000). D. fulgens was also observed to acquire a leather-like appearance

310 following reproduction events and stopped filtering throughout summer. Similarly,

311 most Mediterranean ascidians with resting forms reproduce before summer (e.g.

312 Polysyncraton lacazei, Turon and Becerro 1992; Clavelina lepadiformis, de Caralt et

313 al. 2002; Cystodytes dellechiajei, López-Legentil et al. 2005; Pycnoclavella brava,

314 Pérez-Portela et al. 2007), while the few exceptions correspond to Atlanto-

315 Mediterranean species (e.g. Applidium aff. conicum, Turon and Becerro 1992; 
316 Pycnoclavella communis, Pérez-Portela et al. 2007). What happens while a colony is

317 resting is unknown in most cases and depends on the species (Burighel et al. 1976;

318 Turon 1992). For the only didemnid ascidian investigated in the Mediterranean,

319 Polysyncraton lacazei, Turon (1992) suggested that a 'rejuvenative' process took

320 place during the resting period and involved the regression of old thoraces and

321 budding of new ones. Further studies are needed to establish whether the same

322 phenomenon occurs in D. fulgens. A thorough understanding of the physiological

323 processes involved in the development of resting forms, will cast light on the

324 implications of these processes for ascidian health, long-term survival, and space

325 occupation and maintenance.

326 Colonial ascidians are characterized by their capacity to divide and form

327 smaller colonies (fission) and to grow rapidly by merging previously independent

328 units (fusion). Fragment dynamics are high in some tropical and temperate didemnids

329 (Bak et al. 1981; Ryland et al. 1984; Stocker 1991). In D. fulgens, these processes

330 were moderate, although they occurred all year round with a maximum of fissions

331 recorded in fall and fusions in spring. In other Mediterranean ascidians, clear seasonal

332 patterns in the occurrence of fission and fusion events were not observed (e.g.

333 Cystodytes dellechiajei, López-Legentil et al. 2005). Fusion has been reported to be a

334 mechanism by which some ascidians species achieve the minimal colony size

335 necessary for reproduction (Ritzmann et al. 2009). Accordingly, fusions in D. fulgens

336 were more common in spring and early summer, coinciding with the reproduction

337 period of this species. Further, several studies have demonstrated that smaller colonies

338 of ascidians exhibit faster growth rates (Stocker 1991; Turon and Becerro 1992;

339 López-Legentil et al. 2005). In D. fulgens, fissions were more common when growth

340 rates were higher, indicating that most of the growth was conducted by smaller 
341 colonies. Active growth of smaller colonies would also allow this species to rapidly

342 colonize space left by regressing sessile invertebrates during summer. This strategy

343 may confer an important competitive edge to $D$. fulgens over other species, as shown

344 by the overall increase on total surface area observed during the study period and the 345 observed proliferation of this species during the last decade.

346 Resource allocation to reproduction or growth depends on the requirements of 347 an organism in a given environment and its energy budget within evolutionary and 348 ecological constraints (Cohen 1971; Kozlowski 1992). Mounting evidence indicates 349 that seasonal partitioning of available resources for either growth or reproduction is a 350 common strategy among colonial ascidians in the Mediterranean Sea (López-Legentil 351 et al. 2005; Pérez-Portela et al. 2007). These trade-offs in resource allocation may be 352 linked to temperature changes, nutrient availability and/or 'sexual exhaustion' after 353 larval brooding has drained all nutrient reserves (Berrill 1935; López-Legentil et al. 354 2007). Brooding strategies in colonial ascidians range from the production of a few 355 large and complex larvae per zooid to many small and simple larvae (i.e. larvae with 356 undifferentiated tissues). Reproductive investment per zooid has been shown to be 357 significantly higher in species that produced few well-developed larvae, especially 358 members of the family Didemnidae (Tarjuelo and Turon 2004). As D. fulgens 359 produces a single larva per zooid, we hypothesize that investment in reproduction for 360 this species is high and that little to no energy is available for other biological 361 functions (i.e. growth) during its reproductive period. A temporal trade-off between 362 growth and reproduction, where the latter acted as the major energy sink, was 363 previously described for another colonial ascidian in the Mediterranean Sea (López364 Legentil et al. 2007) and may be a common strategy among species with high 365 reproductive investment. 
366 In this study, we provided the first data on reproductive and growth cycles of a

367 proliferating didemnid ascidian in the Western Mediterranean. As reported for other

368 colonial ascidian species, the life cycle of $D$. fulgens presented a marked seasonality

369 and suggested resource partitioning between reproduction and growth. Seasonal

370 patterns in fission and fusion events were coincident with higher growth rates and the

371 onset of the reproductive periods, respectively, and may contribute to the optimization

372 of resource allocation and ecological success of $D$. fulgens. Overall, colonies

373 increased in surface area during the study period, continuing the expansion observed

374 for this species during the last decade that may displace other common species in the

375 rocky infralittoral. There is a lack of information on ascidian life cycles and their

376 response to current and future fluctuations in abiotic factors. Although primarily

377 descriptive, this information is critical to understand how further natural and

378 anthropological perturbations may affect the distribution and abundance of these

379 animals and the consequences of species expansions on benthic community diversity

380 in the Mediterranean Sea.

381

382 Acknowledgements. We thank Iosune Uriz, Sonia de Caralt and Janina González

383 (CEAB-CSIC) for providing some of the samples. This research was funded by the

384 Marie Curie International Reintegration Grant FP7-PEOPLE-2010-RG 277038 within

385 the $7^{\text {th }}$ European Community Framework Program, the Spanish Government projects

386 CTM2010-17755 and CTM2010-22218, and the Catalan Government grant

387 2009SGR-484 for Consolidated Research Groups.

388

389

\section{References}

390 
391 Agell G, Turon X, De Caralt S, López-Legentil S, Uriz MJ \& 2004. Molecular and

392

393

394

395

396

397

398

399

400

401

402

403

404

405

406

407

408

409

410

411

412

413

414 organism biomarkers of copper pollution in the ascidian Pseudodistoma crucigaster. Marine Pollution Bulletin 48:759-767.

Azumi K, Amano S, Sabau SV, Kamimura A, Satoh N \& Koyanagi R. 2008. Application of ascidian DNA microarray analysis for risk assessment of marine chemical pollutants. In: Interdisciplinary studies on environmental chemistry - Biological responses to chemical pollutants. Murakami Y, Nakayama K, Kitamura S-I, Iwata H, Tanabe S, eds. pp. 107-110. Terrapub.

Bak RPM, Sybesma J \& van Duyl FC. 1981. The ecology of the tropical compound ascidian Trididemnum solidum. II. Abundance, growth and survival. Marine Ecology Progress Series 6:43-52.

Balata D, Nesti U, Piazzi L \& Cinelli F. 2007. Patterns of spatial variability of seagrass epiphytes in the north-west Mediterranean Sea. Marine Biology 151:2025-2035.

Bates WR. 2005. Environmental factors affecting reproduction and development in ascidians and other protochordates. Canadian Journal of Zoology 83:51-61.

Berrill NJ. 1935. Studies in tunicate development. Part III. Differential retardation and acceleration. Philosophical Transactions of the Royal Society of London. Series B, Biological Sciences 225:255-326.

Berrill NJ. 1951. Regeneration and budding in tunicates. Biological Reviews 26:456476.

Bishop DD \& Sommerfeldt AD. 1999. Not like Botryllus: Indiscriminate postmetamorphic fusion in a compound ascidian. Proceedings of the Royal Society of London 266:241-248. 
415 Burighel P, Brunetti R \& Zaniolo G. 1976. Hibernation of the colonial ascidian

416 Botrylloides leachi (Savigny): Histological observations. Bolletino di zoologia $417 \quad 43: 293-301$.

418 Carman MR. 2007. Water quality, nitrogen pollution, and ascidian diversity in coastal 419 waters of southern Massachusetts, USA. Journal of Experimental Biology and $420 \quad$ Ecology 342:175-178.

421 Carman MR, Morris JA, Karney RC \& Grunden DW. 2010. An initial assessment of 422 native and invasive tunicates in shellfish aquaculture of the North American 423 east coast. Journal of Applied Ichthyology 26:8-11.

424 Cohen D. 1971. Maximizing final yield when growth is limited by time or by limiting 425 resources. Journal of Theoretical Biology 33:299-307.

426 Coma R \& Ribes M. 2003. Seasonal energetic constraints in Mediterranean benthic 427 suspension feeders: effects at different levels of ecological organization. Oikos $428 \quad 101: 205-215$.

429 Coma R, Ribes M, Gili J-M \& Zabala M. 2000. Seasonality in coastal benthic 430 ecosystems. Trends in Ecology and Evolution 15:448-453.

431 de Caralt S, López-Legentil S, Tarjuelo I, Uriz JM \& Turon X. 2002. Contrasting 432 biological traits of Clavelina lepadiformis (Ascidiacea) populations from 433 inside and outside harbours in the western Mediterranean. Marine Ecology $434 \quad$ Progress Series 244:125-137.

435 Dias GM, Delboni CG \& Duarte L. 2008. Effects of competition on sexual and clonal 436 reproduction of a tunicate: the importance of competitor identity. Marine 437 Ecology Progress Series 362:149-156. 
438 Dijkstra J, Sherman H \& Harris LG. 2007. The role of colonial ascidians in altering

439 biodiversity in marine fouling communities. Journal of Experimental Biology

$440 \quad$ and Ecology 342:169-171.

441 Dijkstra JA \& Harris LG. 2009. Maintenance of diversity altered by a shift in

442 dominant species: implications for species coexistence. Marine Ecology

$443 \quad$ Progress Series 387:71-80.

444 Erwin PM, López-Legentil S \& Schuhmann PW. 2010. The pharmaceutical value of

445 marine biodiversity for anti-cancer drug discovery. Ecological Economics

$446 \quad 70: 445-451$.

447 Fiore CL \& Cox Jutte P. 2010. Characterization of macrofaunal assemblages

448 associated with sponges and tunicates collected off the southeastern United

449 States. Invertebrate Biology 129:105-120.

450 Fukuda T \& Hirose E. 2008. Differences in associated crustacean fauna and

451 seasonality of sexual reproduction between two color morphs of the

452 photosymbiotic ascidian Didemnum molle (Ascidiacea: Didemnidae). BioOne

$453 \quad 62: 309-316$.

454 Hernández-Zanuy A, García-Cagide A, Esquivel M \& Blanco A. 2000. Reproducción

455 y desarrollo de Ecteinascidia turbinata (Ascideacea: Perophoridae) en Cuba

$456 \quad$ Revista de Biología Tropical 48.

457 Hewitt CL, Gollasch S \& Minchin D. 2009. The vessel as a vector - Biofouling,

458 ballast water and sediments. In: Biological invasions in marine ecosystems.

459 Rilov GR, Crooks JA, eds. pp. 117-131. Springer-Verlag, Berlin Heidelberg.

460 Kozlowski J. 1992. Optimal allocation of resources to growth and reproduction:

461 Implications for age and size at maturity. Trends in Ecology and Evolution

$462 \quad 7: 15-19$. 
463 Kremer LP, Rocha RM \& Roper JJ. 2010. An experimental test of colonization ability

464 in the potentially invasive Didemnum perlucidum (Tunicata, Ascidiacea).

$465 \quad$ Biological Invasions 12:1581-1590.

466 Lafargue F. 1976. Révision taxonomique des Didemnidae des côtes de France

467 (Ascidies composées). Les espèces de Banyuls-Sur-Mer. Genre Didemnum.

468 Deuxième partie: Larves a deux ventouses. Annales de l'Institut

$469 \quad$ Océanographique 52:259-281.

470 Lafargue F \& Wahl M. 1987. The didemnid ascidian fauna of France. Annales de

471 l'Institut Océanographique 63:1-46.

472 Lambert CC. 2005. Historical introduction, overview, and reproductive biology of the 473 protochordates. Canadian Journal of Zoology 83:1-7.

474 Lambert G. 2009. Adventures of a sea squirt sleuth: unraveling the identity of

475 Didemnum vexillum, a global ascidian invader. Aquatic Invasions 4:5-28.

476 López-Legentil S, Bontemps-Subielos N, Turon X \& Banaigs B. 2007. Secondary

477 metabolite and inorganic contents in Cystodytes sp. (Ascidiacea): temporal

478 patterns and association with reproduction and growth. Marine Biology

$479 \quad 151: 293-299$.

480 López-Legentil S, Ruchty M, Domenech A \& Turon X. 2005. Life cycles and growth 481 rates of two morphotypes of Cystodytes (Ascidiacea) in the western

482 Mediterranean. Marine Ecology Progress Series 296:219-228.

483 Marshall DJ, Cook CN \& Emlet RB. 2006. Offspring size effects mediate competitive 484 interactions in a colonial marine invertebrate. Ecology 87:214-225.

485 Millar RH. 1971. The biology of ascidians. Advances in Marine Biology 9:1-100.

486 Molin E, Gabriele M \& Brunetti R. 2003. Further news on hard substrate communities 487 of the northern Adriatic Sea with data on growth and reproduction in Polycitor 
488

489

490

491

492

493

494

495

496

497

498

499

500

501

502

503

504

505

506

507

508

509

510

511

adriaticus (Von Drasche, 1883). Bollettino del Museo Civico di Storia Naturale di Venezia 54:19-28.

Newlon III AW, Yund PO \& Stewart-Savage J. 2003. Phenotypic plasticity of reproductive effort in a colonial ascidian, Botryllus schlosseri. Journal of Experimental Zoology 297:180-188.

Pérez-Portela R, Palacín C, Duran S \& Turon X. 2007. Biological traits of three closely related species of Pycnoclavella (Ascidiacea) in the Western Mediterranean. Marine Biology 152:1031-1038.

Rinkevich B. 2005. Natural chimerism in colonial urochordates. Journal of Experimental Biology and Ecology 322:93-109.

Rinkevich B \& Saito Y. 1992. Self-nonself recognition in the colonial protochordate Botryllus schlosseri from Mutsu Bay, Japan. Zoological Science 9:983-988.

Ritzmann NF, da Rocha RM \& Roper JJ. 2009. Sexual and asexual reproduction in Didemnum rodriguesi (Ascidiacea, Didemnidae). Iheringia, Série Zoologia 99:106-110.

Rius M, Turon X, Dias GM \& Marshall DJ. 2010. Propagule size effects across multiple life-history stages in a marine invertebrate. Functional Ecology $24: 685-693$.

Rodriguez LF \& Ibarra-Obando SE. 2008. Cover and colonization of commercial oyster (Crassostrea gigas) shells by fouling organisms in San Quintin Bay, Mexico. BioOne 27:337-343.

Ryland JS, Wigley RA \& Muirhead A. 1984. Ecology and colonial dynamics of some Pacific reef flat Didemnidae (Ascidiacea). Zoological Journal of the Linnean Society $80: 261-282$. 
512 Saito Y, Hirose E \& Watanabe H. 1994. Allorecognition in compound ascidians.

513 International Journal of Developmental Biology 38:237-247.

514 Shenkar N, Bronstein O \& Loya Y. 2008. Population dynamics of a coral reef

515 ascidian in a deteriorating environment. Marine Ecology Progress Series

$516 \quad 367: 163-171$.

517 Shenkar N \& Loya Y. 2008. The solitary ascidian Herdmania momus: native (Red

518 Sea) versus non-indigenous (Mediterranean) populations. Biological

$519 \quad$ Invasions:1-9.

520 Smale DA \& Childs S. 2012. The occurrence of a widespread marine invader,

521 Didemnum perlucidum (Tunicata, Ascidiacea) in Western Australia.

$522 \quad$ Biological Invasions 14:1325-1330.

523 Stefaniak L, Lambert G, Gittenberger A, Zhang H, Lin S \& Whitlatch RB. 2009.

524 Genetic conspecificity of the worldwide populations of Didemnum vexillum

$525 \quad$ Kott, 2002. Aquatic Invasions 4:29-44.

526 Stefaniak L, Zhang H, Gittenberger A, Smith K, Holsinger K, Lin S \& Whitlatch RB.

527 2012. Determining the native region of the putatively invasive ascidian

528 Didemnum vexillum Kott, 2002. Journal of Experimental Marine Biology and

$529 \quad$ Ecology 422-423.

530 Stocker LJ. 1991. Effects of size and shape of colony in rates of fission, fusion,

531 growth and mortality in a subtidal invertebrate. Journal of Experimental

$532 \quad$ Biology and Ecology 149:161-175.

533 Stocker LJ \& Underwood AJ. 1991. The relationship between the presence of

534 neighbours and rates of sexual and asexual reproduction in a colonial

535 invertebrate. Journal of Experimental Biology and Ecology 149:191-205. 
536 Svane IB \& Young CM. 1989. The ecology and behaviour of ascidian larvae.

537 Oceanography and Marine Biology: Annual Reviews 27:45-90.

538 Tarjuelo I \& Turon X. 2004. Resource allocation in ascidians: reproductive

539 investment vs. other life-history traits. Invertebrate Biology 123:168-180.

540 Turner SJ, Thrush SF, Cummings VJ, Hewitt JE, Wilkinson MR, Williamson RB \&

541 Lee DJ. 1997. Changes in epifaunal assemblages in response to marina

542 operations and boating activities. Marine Environmental Research 43:181-199.

543 Turon X. 1988. The ascidians of Tossa de Mar (NE Spain). II.- Biological cycles of

544 the colonial species. Cahiers de Biologie Marine 29:407-418.

545 Turon X. 1992. Periods of non-feeding in Polysyncraton lacazei (Ascidiacea:

546 Didemnidae): a rejuvenative process? Marine Biology 112:647-655.

547 Turon X \& Becerro MA. 1992. Growth and survival of several ascidian species from

548 the northwestern Mediterranean. Marine Ecology Progress Series 82:235-247.

549 Westerman EL, Dijkstra JA \& Harris LG. 2009. High natural fusion rates in a

$550 \quad$ botryllid ascidian. Marine Biology 156:2613-2619.

551

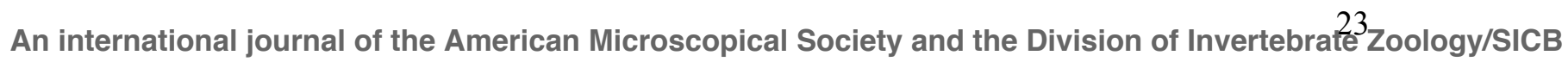


$552 \quad$ Figure legends

553

554 Figure 1. Annual reproductive cycle in Didemnum fulgens and ambient seawater

555 temperature over the monitoring period. The percentage of zooids in different

556 reproductive stages (mean of 10 zooids per colony, 5 colonies per month) are shown

557 for each month, with stars indicating the presence of larvae in the colonies. Empty

558 columns correspond to months without data and temperature data (dashed line) are

559 superimposed.

560

561 Figure 2. Time course of maturity index (MI) evolution in Didemnum fulgens. Error

562 bars represent \pm 1 standard error and temperature data (dashed line) are superimposed.

563

564 Figure 3. Cross-correlations analysis between the maturity index and temperature, 565 with time lag in months. Curved lines indicate significant positive (upper) and 566 negative (lower) correlation values.

567

568 Figure 4. In situ photographs of a Didemnum fulgens colony monitored for growth in 569 the Western Mediterranean. (A) Resting form in July 2011, and (B) the same colony 570 in January 2012. Scale bar $=2 \mathrm{~cm}$.

571

572 Figure 5. Mean cumulative growth of Didemnum fulgens over time in the surveyed 573 area. Error bars represent \pm 1 standard error.

574

575 Figure 6. Monthly growth rates of Didemnum fulgens and seawater temperature over 576 time. Error bars represent \pm 1 standard error. 
578 Figure 7. Number of fusion (dark gray bars) and fission (light gray bars) events

579 recorded during the monitoring period, with monthly growth rates (line)

580 superimposed. Error bars represent \pm 1 standard error.

581

582 Figure 8. Cross-correlations analyses between (A) growth rate and temperature, and

583 (B) maturity index and growth rate, with time lag in months. Curved lines indicate

584 significant positive (upper) and negative (lower) correlation values.

585 
Annual reproductive cycle in Didemnum fulgens and ambient seawater temperature over the monitoring period. The percentage of zooids in different reproductive stages (mean of 10 zooids per colony, 5 colonies per month) are shown for each month, with stars indicating the presence of larvae in the colonies. Empty columns correspond to months without data and temperature data (dashed line) are superimposed. $352 \times 264 \mathrm{~mm}(72 \times 72 \mathrm{DPI})$ 


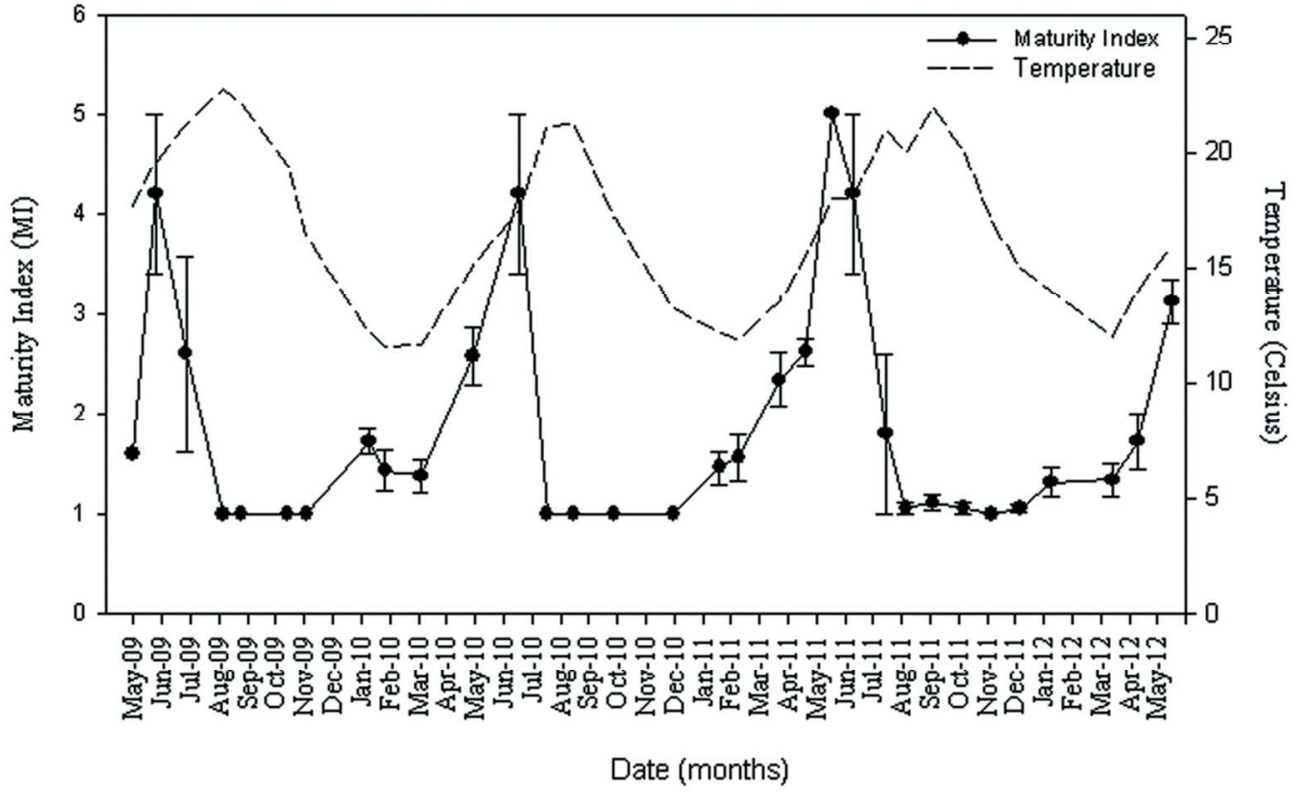

Time course of maturity index (MI) evolution in Didemnum fulgens. Error bars represent \pm 1 standard error and temperature data (dashed line) are superimposed. $96 \times 64 \mathrm{~mm}(300 \times 300 \mathrm{DPI})$ 


\section{Cross-correlations analysis between the maturity index and temperature, with time lag in months. Curved} lines indicate significant positive (upper) and negative (lower) correlation values. $264 \times 382 \mathrm{~mm}(72 \times 72 \mathrm{DPI})$ 
In situ photographs of a Didemnum fulgens colony monitored for growth in the Western Mediterranean. (A) Resting form in July 2011, and (B) the same colony in January 2012. Scale bar $=2 \mathrm{~cm}$. $140 \times 60 \mathrm{~mm}(300 \times 300 \mathrm{DPI})$ 


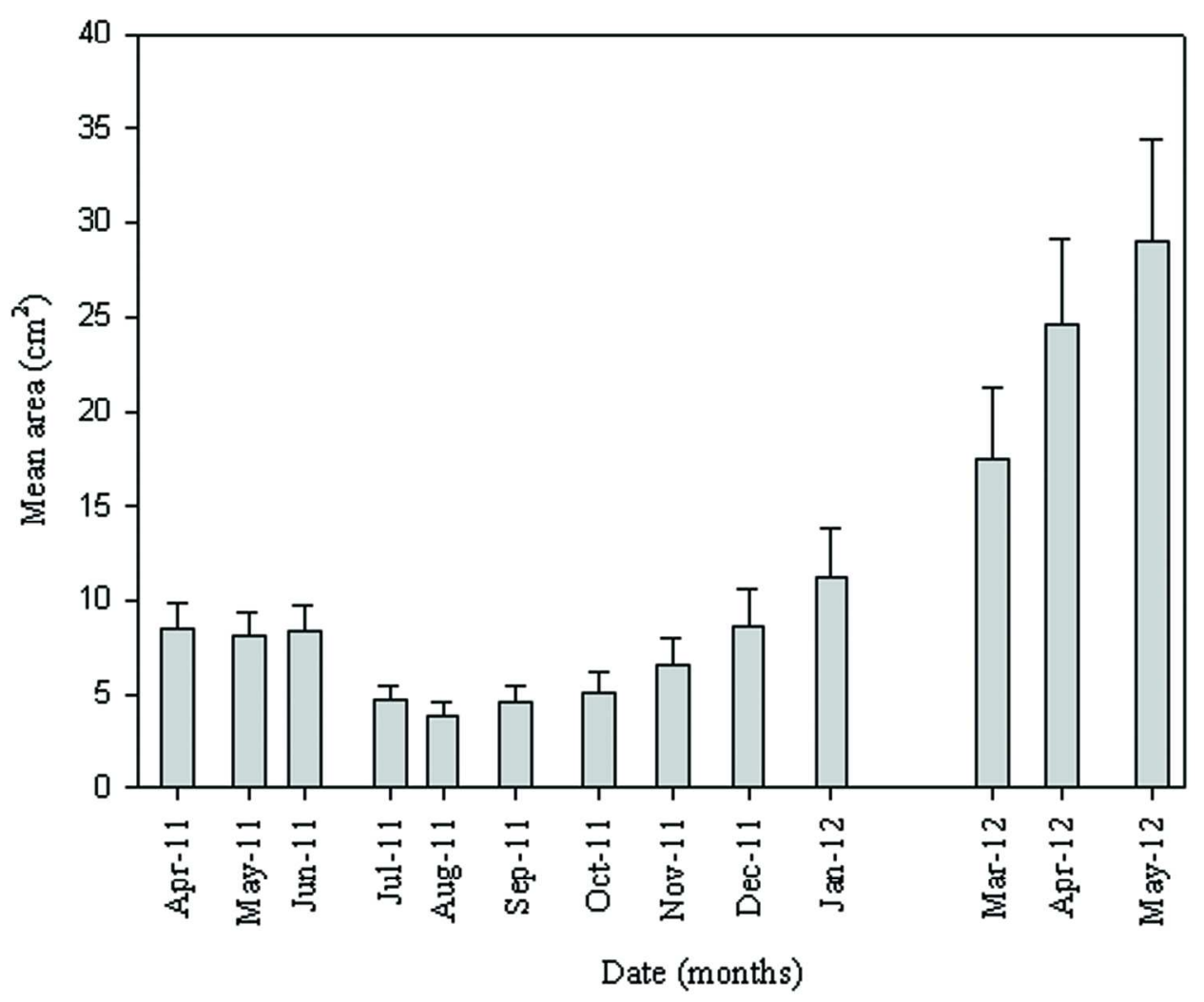

Mean cumulative growth of Didemnum fulgens over time in the surveyed area. Error bars represent \pm 1 standard error. $152 \times 132 \mathrm{~mm}(300 \times 300$ DPI $)$ 


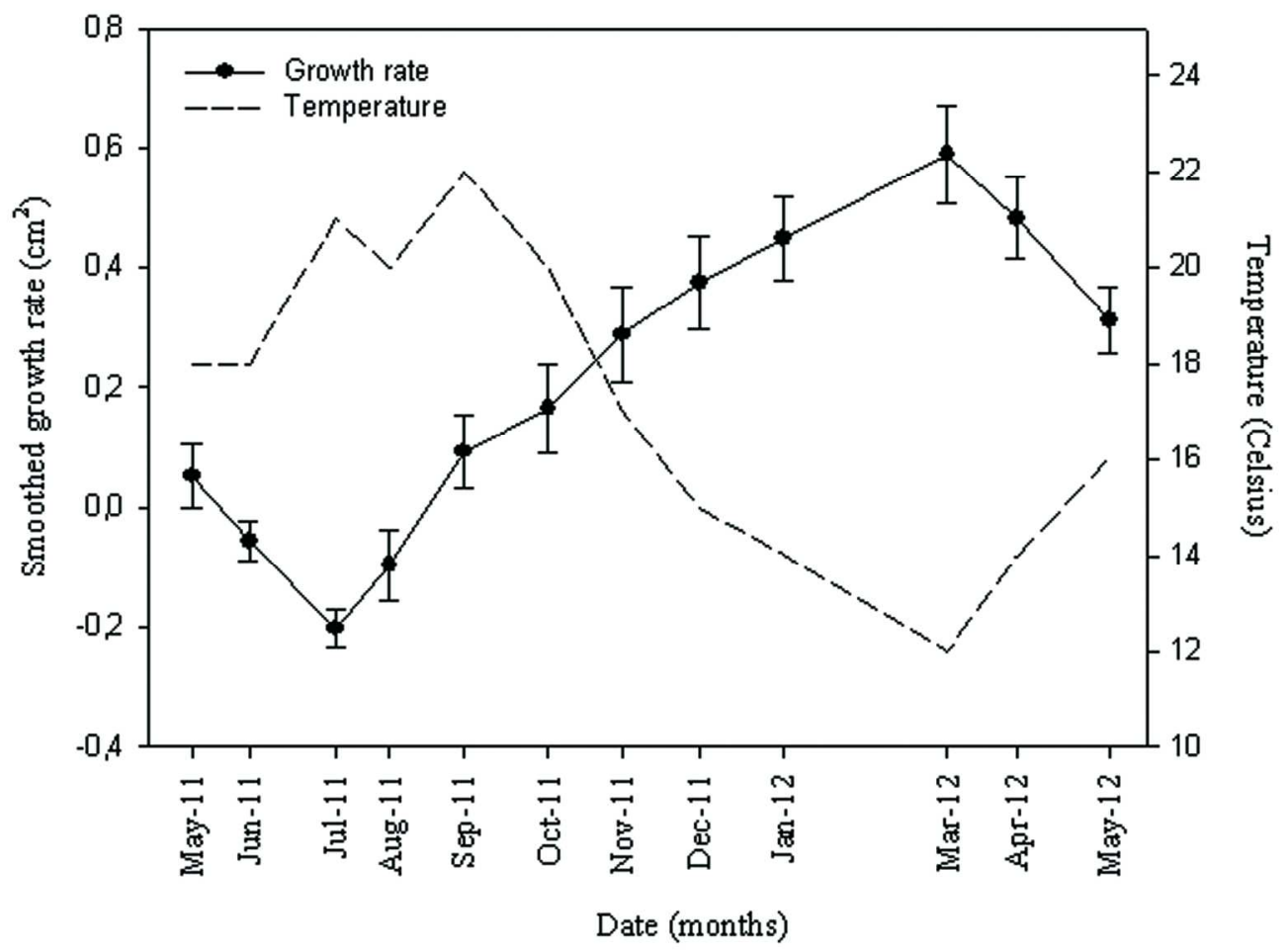

Monthly growth rates of Didemnum fulgens and seawater temperature over time. Error bars represent \pm 1 standard error. $152 \times 122 \mathrm{~mm}(300 \times 300 \mathrm{DPI})$ 
Number of fusion (dark gray bars) and fission (light gray bars) events recorded during the monitoring period, with monthly growth rates (line) superimposed. Error bars represent \pm 1 standard error. $352 \times 264 \mathrm{~mm}(72 \times 72 \mathrm{DPI})$ 
Cross-correlations analyses between (A) growth rate and temperature, and (B) maturity index and growth rate, with time lag in months. Curved lines indicate significant positive (upper) and negative (lower) correlation values. $264 \times 382 \mathrm{~mm}(72 \times 72 \mathrm{DPI})$ 